\title{
Advanced anticorrosive coatings prepared from electroactive polyimide/graphene nanocomposites with synergistic effects of redox catalytic capability and gas barrier properties
}

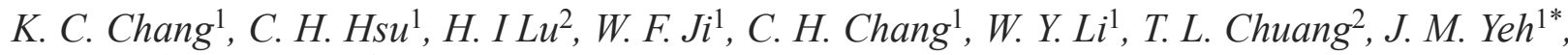 \\ W. R. Liu $^{3}$, M. H. Tsai \\ ${ }^{1}$ Department of Chemistry, Center for Nanotechnology and Biomedical Technology at Chung-Yuan Christian University \\ (CYCU), Chung Li, 32023 Taiwan, Taiwan \\ ${ }^{2}$ Master Program in Nanotechnology and Center for Nanotechnology at CYCU, Chung Li, 32023 Taiwan, Taiwan \\ ${ }^{3}$ Department of Chemical Engineering, CYCU, Chung Li, 32023 Taiwan, Taiwan \\ ${ }^{4}$ Department of Chemical and Materials Engineering, National Chin-Yi University of Technology, Taichung, 41170 \\ Taiwan, Taiwan
}

Received 27 September 2013; accepted in revised form 30 November 2013

\begin{abstract}
In this study, electroactive polyimide (EPI)/graphene nanocomposite (EPGN) coatings were prepared by thermal imidization and then characterized by Fourier transformation infrared (FTIR) and transmission electron microscope (TEM). The redox behavior of the as-prepared EPGN materials was identified by in situ monitoring for cyclic voltammetry (CV) studies. Demonstrating that EPGN coatings provided advanced corrosion protection of cold-rolled steel (CRS) electrodes as compared to that of neat EPI coating. The superior corrosion protection of EPGN coatings over EPI coatings on CRS electrodes could be explained by the following two reasons. First, the redox catalytic capabilities of amino-capped aniline trimer (ACAT) units existing in the EPGN may induce the formation of passive metal oxide layers on the CRS electrode, as indicated by scanning electron microscope (SEM) and electron spectroscopy for chemical analysis (ESCA) studies. Moreover, the well-dispersed carboxyl-graphene nanosheets embedded in the EPGN matrix hinder gas migration exponentially. This would explain enhanced oxygen barrier properties of EPGN, as indicated by gas permeability analysis (GPA) studies.
\end{abstract}

Keywords: nanocomposites, electroactive, polyimide, graphene, anticorrosion

\section{Introduction}

Polymer-based composites were reported in the 1960 s as a new paradigm in material science. In the past twenty years, three major inorganic materials acting as nanofillers have been used to prepare organic-inorganic nanocomposites: (1) layered materials such as clay $[1,2]$, (2) tubular materials such as carbon nanotubes (CNTs) [3, 4], and (3) spherical materials such as $\mathrm{SiO}_{2}$ particles $[5,6]$ as well as other synthetic materials $[7,8]$.
Owing to the poor compatibility between the organic matrix and the inorganic nanofillers, it is typically desired to ameliorate the compatibility at the matrix/ filler interface, ideally during the preparation of the nanocomposite materials. Thus, it is of great importance to innovative new nanofiller materials or new methods for the preparation of polymer/nanofiller composites is key in developing novel advanced polymer-based composites.

\footnotetext{
${ }^{*}$ Corresponding author, e-mail: juiming@cycu.edu.tw (C) BME-PT
} 
Polyimides (PIs) are well-known high-performance polymeric materials due to desirable tensile properties; high-temperature durability, excellent chemical and thermal stabilities, low thermal expansion coefficient, and low dielectric constant [9-12].

The electroactive oligoaniline were exploited to provide various polymers such as PIs and other derived polymers $[13,14]$ with electroactive properties. The incorporation of a well-defined oligoaniline into the backbone structure of a PI could render a novel electroactive PI possess electroactivity, much better mechanical properties, and thermal stability. Rcently, we have reported the synthesis of an EPI with oligoaniline in the main chain via a thermal imidization reaction and further introduced nanomaterials (e.g., clay nanosheets and $\mathrm{TiO}_{2}$ nanoparticles) into the EPI to prepare EPI nanocomposites [15, 16]. All the examined materials exhibited significant enhancement of the corrosion protection of the metallic substrate as compared with that of neat electroactive polymer coatings $[17,18]$ since the well-dispersed nanoclay in the EPI with an aspect ratio of $\sim 200$ increasing the length of the diffusion pathways for reactive gases (e.g., oxygen and water vapor) in the polymers [15].

Extensive efforts are devoted to utilizing graphenebased materials such as graphene nanoplatelets (GNPs), graphene nanosheets (GNSs), and graphene oxide (GO) as nanofillers to improve the mechani$\mathrm{cal}$, thermal and dielectric properties, and electricity of diverse organic polymers [19-26] since scientists discovered excellent intrinsic properties of graphene sheets. Nowadays, scientific studies associated with the lower density and higher aspect ratio $(\sim 500)$ [27] of conductive graphene, compared with that of nonconductive clay platelets initiated investigation into their potential application as advanced gas barrier and corrosion-prevention polymer nanocomposites. To the best of our knowledge, there is no report in investigating the anticorrosive abilities of the EPI nanocomposites with the addition of graphene nanosheets. In this study, we fabricated anticorrosive EPI/ graphene nanocomposite (EPGN) coatings which could provide two-fold protection against metal corrosion. In the first step of the protection mechanism, the electroactive amino-capped aniline trimer (ACAT) components in EPI form a passivation oxide layer on the metal surface. Secondly, the well-dispersed carboxyl-graphene nanosheets in the EPI matrix increase the tortuosity of the diffusion pathway of $\mathrm{O}_{2}$ molecules. The detailed anticorrosion performance of the EPGN coated onto cold-rolled steel (CRS) was evaluated through a series of electrochemical corrosion measurements in a corrosive medium ( $3.5 \mathrm{wt} \%$ sodium chloride aqueous solution).

\section{Experimental section}

\subsection{Chemicals and instruments}

Aniline (Fluka, Germany) was distilled prior to use. 1,4-phenylenediamine (Aldrich, Germany), 4'-(4,4'isopropylidene-diphenoxy)bis(phthalic anhydride) (BSAA, Aldrich, Germany), 4,4-oxydianiline (ODA, Aldrich, Germany), and $N, N$-dimethylacetamide (DMAc, Riedel-deHaën, Germany) were used as received without further purification. Graphene nanosheets (SFG44-GNS) were prepared from SFG44 synthetic graphite powder $\left(\mathrm{TIMCAL}^{\circledR}\right)$. All reagents were reagent grade unless otherwise stated.

Fourier transform infrared (FTIR) spectra were recorded using a FTIR spectrometer (JASCO FT/IR4100 , Japan) operated at room temperature. The nanostructure of the composite materials was imaged with a JEOL-200FX transmission electron microscope (TEM, Japan). The samples for TEM observations were cut into 60-90-nm-thick sections with a diamond knife. The morphology of the surface of the passivation metal oxide layers was observed using a scanning electron microscope (SEM, JOEL JSM$7600 \mathrm{~F}$, Japan). The corrosion potential and corrosion current of sample-coated cold-rolled steel (CRS) electrodes were electrochemically measured using a VoltaLab 50 potentiostat/galvanostat. Electrochemical impedance spectroscopy (EIS) measurements were recorded on an AutoLab (PGSTAT302N) potentiostat/galvanostat electrochemical analyzer. Gas permeability $\left(\mathrm{O}_{2}\right.$ permeation) experiments were performed using a GTR-31 analyzer (Yangimoto Co., Kyoto, Japan). Electron spectroscopy for chemical analysis (ESCA) was performed using a VG Scientific ESCALAB 250 system.

\subsection{Synthesis and characterization of ACAT}

A typical procedure was recently established by Wei et al. [28] for synthesizing ACAT and accordingly, the ACAT could be easily synthesized by oxidizing 1,4-phenylenediamine and 2 equiv of aniline, with ammonium persulfate as an oxidant. The ACAT 
was characterized using mass spectroscopy, FTIR spectroscopy, and ${ }^{1} \mathrm{H}$ NMR spectroscopy, as previously been reported in the literature [29].

\subsection{Synthesis and characterization of carboxyl-graphene nanosheets}

GO derived from SFG44 synthetic graphite powder (TIMCAL ${ }^{\circledR}$ ) was synthesized by a modified Hummers' method [30]. The few-layer carboxyl-graphene nanosheets were synthesized by thermal exfoliation at $1000^{\circ} \mathrm{C}$.

The surface composition of the carboxyl-graphene nanosheets was examined from the analysis of Xray photoelectron spectroscopy (XPS) spectra, as shown in Figure 1. The characteristic peak was due to the graphitic structure (mainly $\mathrm{C}=\mathrm{C}$ ) at a binding energy of $284.5 \mathrm{eV}$. Moreover, the intense splitting of the $\mathrm{C} 1 \mathrm{~s}$ peak at higher binding energy suggested the presence of oxidized carbon functional groups. The curve showed three oxidized $\mathrm{C} 1 \mathrm{~s}$ peaks centered at $286.1 \mathrm{eV}(\mathrm{C}-\mathrm{O}$ from phenol and ether), $287.5 \mathrm{eV}(\mathrm{C}=\mathrm{O}$ from carbonyl and quinone), and $288.7 \mathrm{eV}$ (-COO from carboxyl and ester). The relative intensity of the $\mathrm{C}-\mathrm{O}$ peak was much larger than those of the $\mathrm{C}=\mathrm{O}$ and $-\mathrm{COOH}$ peaks.

The content of functionalized groups containing carbon-oxygen bonds of carboxyl-graphene nanosheets was calculated from the XPS spectra using the Equation (1) [31]:

Content of functionalized groups containing carbon-oxygen bonds $=$
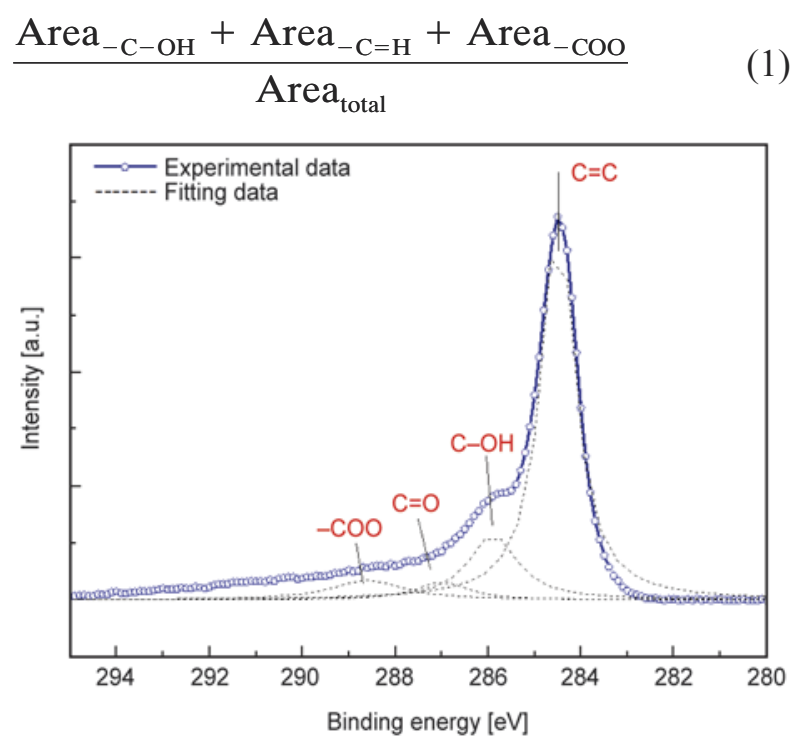

Figure 1. XPS C 1s spectra of carboxyl-graphene
According to the quantitative analysis by Gaussian fitting with three peaks, the $\mathrm{C}-\mathrm{O}, \mathrm{C}=\mathrm{O}$ and $-\mathrm{COO}$ contents of the carboxyl-graphene nanosheets were 11,5 , and $4 \%$, respectively. Graphene nanosheets were also characterized using X-ray diffraction (XRD), Raman spectra, and SEM and TEM observations, under similar conditions as those previously reported $[32,33]$.

\subsection{Preparation of EPGN coatings}

A typical procedure to prepare the EPGN coatings by thermal imidization is as follows. The electroactive poly(amic acid)/graphene (EPAAG) was prepared by reacting with BSAA and ACAT. BSAA $(0.520 \mathrm{~g}, 1 \mathrm{mmol})$ and the ACAT $(0.288 \mathrm{~g}, 1 \mathrm{mmol})$ were separately dissolved in $4.0 \mathrm{~g}$ of DMAc. Subsequently, graphene (e.g. $1 \mathrm{wt} \%$ ) was mixed well with the BSAA solution, and then, the BSAA/graphene and ACAT solutions were mixed under magnetic stirring for $30 \mathrm{~min}$ at room temperature to form EPAAG. Then, EPAAG drops were spread on the $\mathrm{CRS}$, and subsequent thermal imidization was performed at $80^{\circ} \mathrm{C}$ for $0.5 \mathrm{~h}, 100^{\circ} \mathrm{C}$ for $6 \mathrm{~h}, 160^{\circ} \mathrm{C}$ for $2 \mathrm{~h}, 200^{\circ} \mathrm{C}$ for $2 \mathrm{~h}$, and $30^{\circ} \mathrm{C}$ for $6 \mathrm{~h}$ to obtain EPGN coatings. The thickness of coatings is about $30 \mu \mathrm{m}$

\subsection{Electrochemical corrosion studies}

The electrochemical corrosion measurements were performed using a VoltaLab 50 system. All the electrochemical corrosion measurements were performed using a double-wall jacketed cell covered with a glass plate, through which water was maintained at a constant temperature of $25 \pm 0.5^{\circ} \mathrm{C}$. The open-circuit potential (OCP) at the equilibrium state of the system was recorded as the corrosion potential $\left(E_{\text {corr }}\right.$ in $\mathrm{mV}$ versus a saturated calomel electrode (SCE)). Tafel plots were obtained by scanning the potential from -500 to $500 \mathrm{mV}$ above $E_{\text {corr }}$ at a scan rate of $10 \mathrm{mV} / \mathrm{min}$. The corrosion current $\left(I_{\text {corr }}\right)$ was determined by superimposing a straight line along the linear portion of the cathodic or anodic curve and extrapolating it through $E_{\text {corr. }}$ The corrosion rate $\left(R_{\text {corr }}\right.$, in milli-inches per year, MPY) was calculated from the Equation (2):

$R_{\mathrm{corr}}[\mathrm{MPY}]=\frac{0.13 I_{\mathrm{corr}} \cdot E \cdot W .}{A \cdot d}$

where $E . W$. is the equivalent weight [g/eq.], $A$ is the area $\left[\mathrm{cm}^{2}\right]$, and $d$ is the density $\left[\mathrm{g} / \mathrm{cm}^{3}\right]$. 
An AutoLab (PGSTAT302N) potentiostat/galvanostat was used to perform the alternating current (AC) impedance spectroscopy measurements. Impedance was measured in the range $100 \mathrm{kHz}$ to $100 \mathrm{MHz}$ with a $1 \mathrm{~cm} \times 1 \mathrm{~cm}$ pure iron working electrode embedded in epoxy, $\mathrm{Pt}$ as a counter electrode, and an SCE as a reference electrode. The working electrode was initially placed in the test environment for $30 \mathrm{~min}$ prior to the impedance run. All experiments were conducted at room temperature. All trials were repeated at least three times to ensure reproducibility and statistical significance of the raw data.

\subsection{Preparation of membranes and molecular barrier property measurements}

The typical procedure for the preparation of EPGN membranes with 0.5 and $1 \mathrm{wt} \%$ of carboxyl-graphene nanosheets (denoted as EPGN0.5 and EPGN1, respectively) is shown in Figure 2. Membranes of the asprepared EPI and EPGN materials were prepared for measurement of the oxygen barrier property that had been reported in our earlier papers [34, 35].

\section{Results and discussion}

\subsection{Characterization of EPI and EPGN materials}

The successful synthesis of EPI and EPGN materials was confirmed by IR analysis. Figure 3 shows the FTIR spectra of the obtained for ACAT-based EPAA, EPI, and EPGN materials. In all of the FTIR spectra, the characteristic peaks from 2500 to $3500 \mathrm{~cm}^{-1}$ indicate the presence of $\mathrm{O}-\mathrm{H}$ and $\mathrm{N}-\mathrm{H}$. Moreover, the characteristic peaks at 1600 and $1504 \mathrm{~cm}^{-1}$ were assigned to the stretching modes of $\mathrm{N}=\mathrm{Q}=\mathrm{N}$ and $\mathrm{N}-\mathrm{B}-\mathrm{N}$, respectively $(\mathrm{Q}$ represents the quinoid ring, and $\mathrm{B}$ represents the benzene ring structure). In the case of ACAT-based EPAA (Figure 3 curve a), the characteristic peaks for $\mathrm{C}=\mathrm{O}$ in $\mathrm{COOH}$ were found at $1712 \mathrm{~cm}^{-1}$. The EPI characteristic peaks in both EPI and EPGN1, that is, the peaks related to the functional groups of EPAA such as carboxylic acid and amine groups at 2500$3500 \mathrm{~cm}^{-1}$, were absent. The two peaks at 1774 and $1712 \mathrm{~cm}^{-1}$ may be associated with the asymmetric and symmetric carbonyl stretching vibration, respectively, of the imide absorption band, respectively.

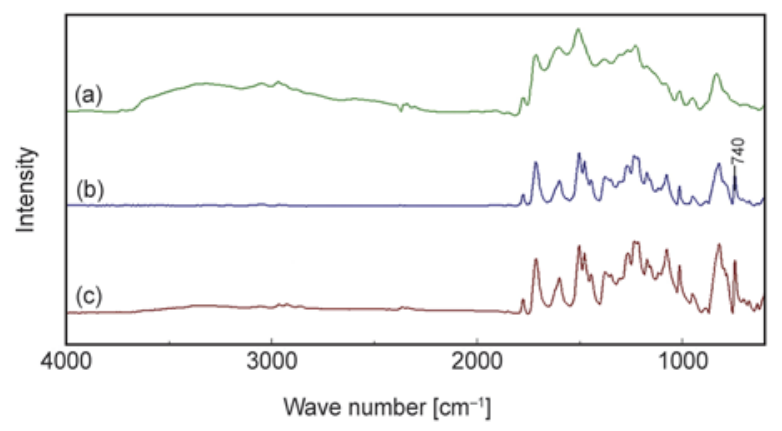

Figure 3. FTIR spectra of (a) EPAA, (b) EPI, and (c) EPGN

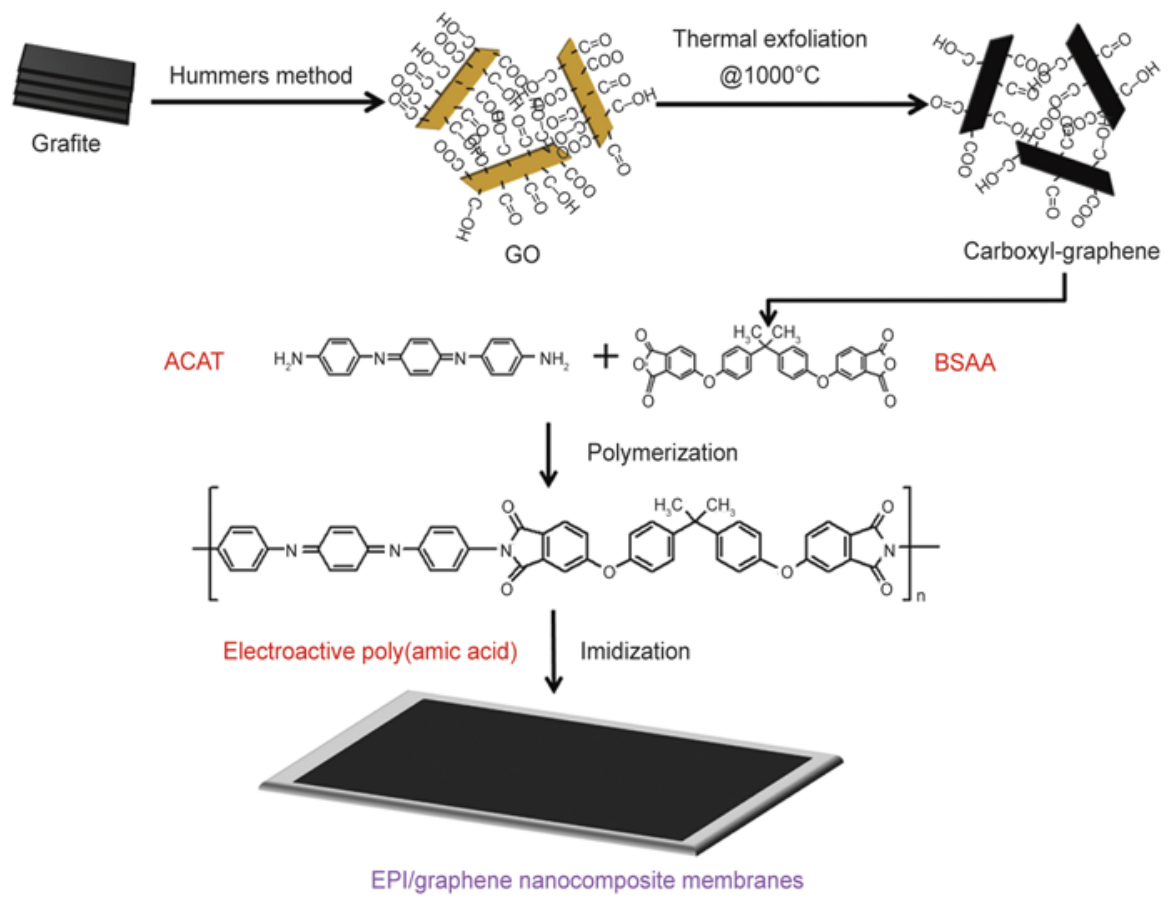

Figure 2. Preparation of EPI/graphene nanocomposite (EPGN) membranes 
Finally, the new peaks at 1373 and $740 \mathrm{~cm}^{-1}$ can be explained by $\mathrm{C}-\mathrm{N}$ stretching and imide ring, respectively. The characteristic absorption band found at $740 \mathrm{~cm}^{-1}$ was the result of the deformation of the imide groups, as shown in Figure 3 curves b and $\mathrm{c}$. These changes in the characteristic peaks of ACAT-based EPAA, EPI, and EPGN indicate that EPAA was almost completely converted into the corresponding ACAT-based EPI and EPGN through the thermal imidization process at $200^{\circ} \mathrm{C}[18,36,37]$. Moreover, comparison of the two curves of the EPI and EPGN materials, no obviously different absorption peak is observed, probably because of the low amounts of graphene present in the samples [38].

\subsection{Morphology of EPGN membranes}

The morphological studies of the dispersion of graphene nanosheets can be identified by TEM observations. Figure 4 shows the micrographs of EPGN1 taken at $200 \mathrm{k}$ magnification using the $120 \mathrm{kV} \mathrm{TEM}$ instrument. The bright regions of the photograph at

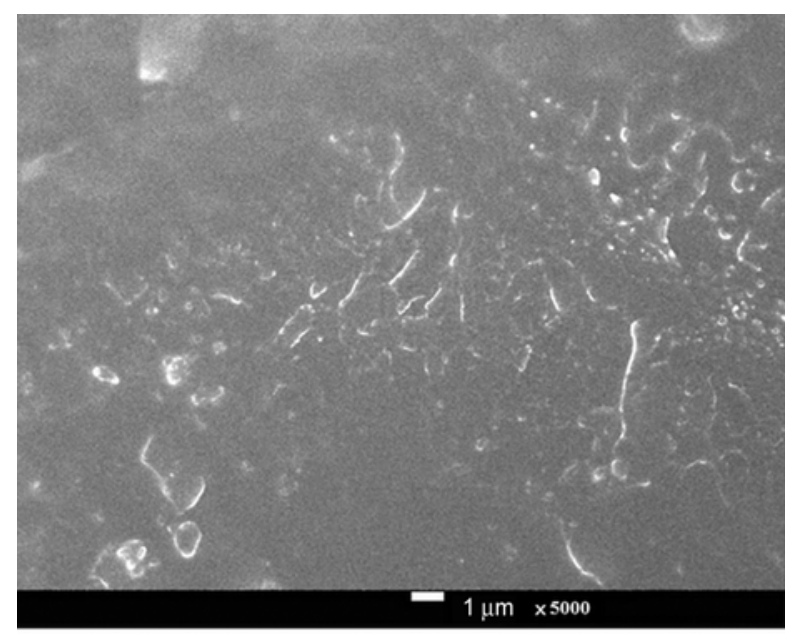

a)

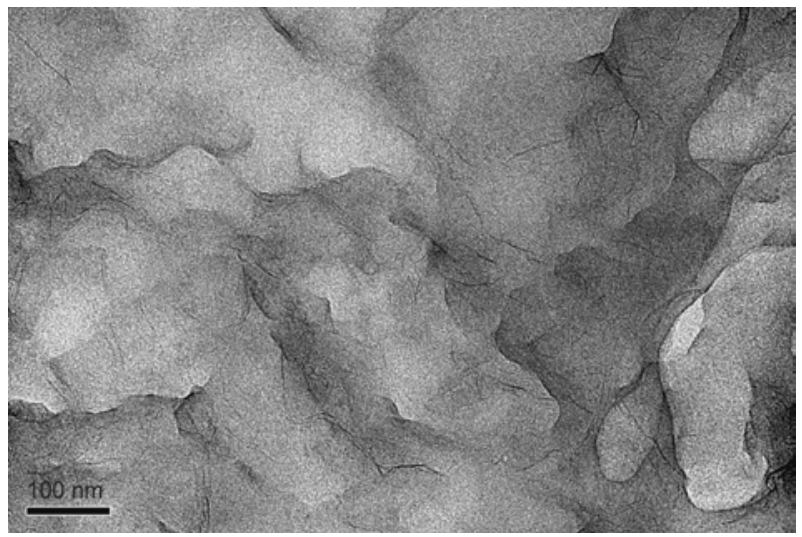

Figure 4. TEM micrographs of EPGN1 ( $\times 200 \mathrm{k})$

high magnification represent the domain of the EPI matrix, and the dark lines correspond to the cross section of the layers of graphene nanosheets. As shown in the figure, EPGN1 exhibited relatively well-dispersed graphene nanosheets in the EPI matrix. This indicates that the attachment of carboxylic groups onto the graphene surface could effectively enhance the compatibility between the car-

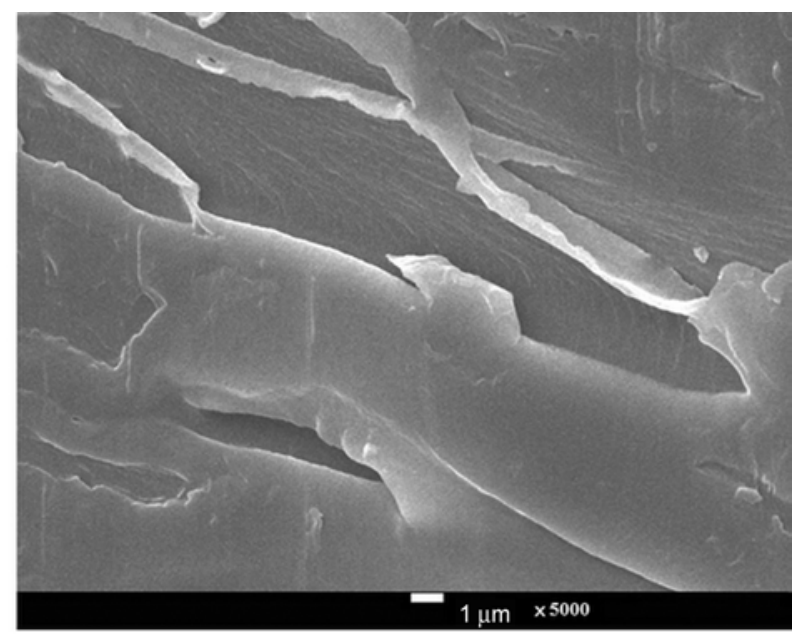

c)

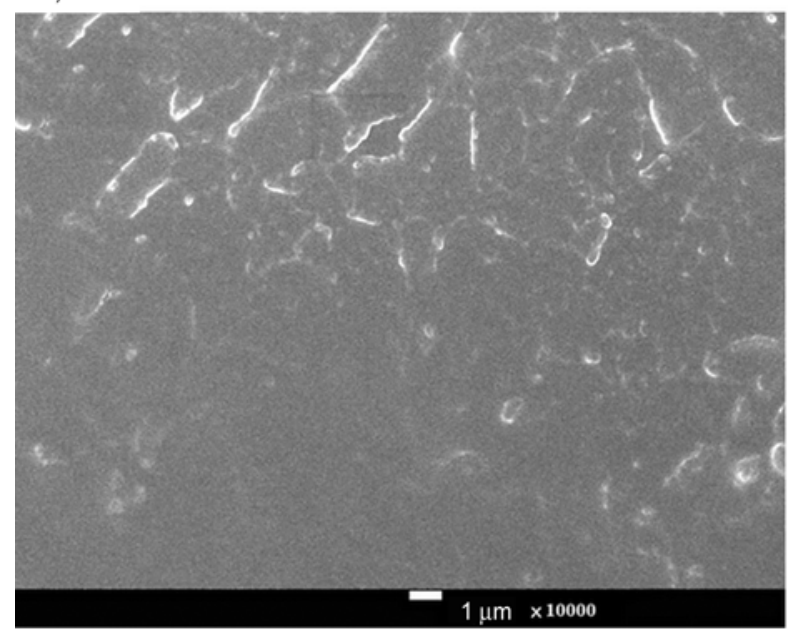

b)

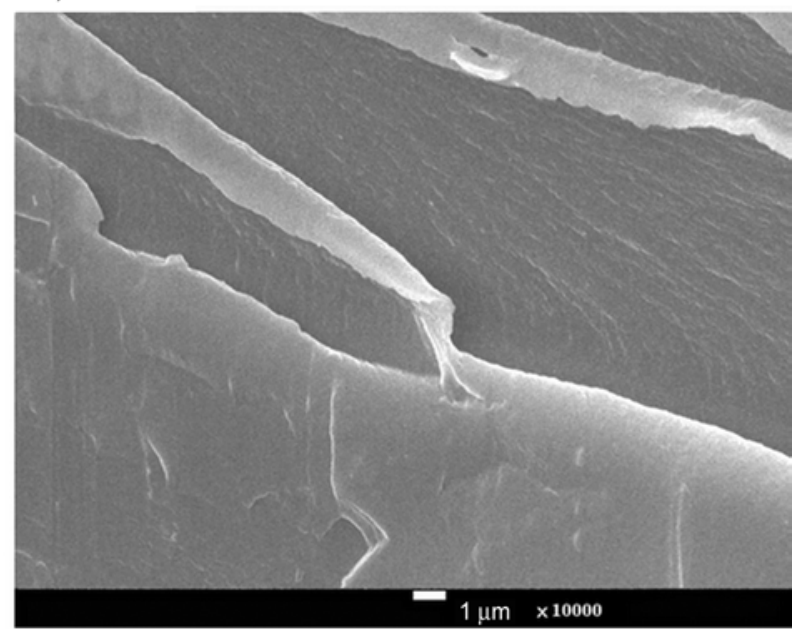

d)

Figure 5. SEM images of fracture surfaces of (a) EPI ( $\times 5$ k), (b) EPI $(\times 10$ k), (c) EPGN1 ( $\times 5$ k), and (d) EPGN1 $(\times 10$ k) 
boxyl-graphene nanosheets and the EPI matrix, leading to improved dispersion capability. The enhanced dispersion can also be attributed to the formation of hydrogen bonds between the remaining hydroxyl groups of the carboxyl-graphene nanosheets and the carboxyl groups of EPAA [39].

The dispersion of graphene nanosheets in the EPI matrix are also shown in the SEM images of the fracture surfaces of membranes in Figure 5. As can be seen in Figure 5a, 5b, EPI film shows a smooth fractured surface. In contrast, the EPGN1 membrane possesses rough fractured surfaces that could be attributed to the strong interfacial adhesion and good compatibility between the EPI matrix and carboxyl-graphene nanosheets (Figure 5c, 5d).

\subsection{Adhesion test}

Void space at the coating-metal interface is responsible for the accumulation of water and ions at the interface, and believed to be a primary failure mechanism for corrosion resistant coatings. Therefore, a corrosion-inhibiting coating should have good adhesion with the protecting surface for its practical application. The adhesion of the EPI and EPGN1 coating on the CRS substrate was evaluated according to the cross-cut method [40]. The results showed that there was no significant peeling of either EPI or EPGN1 after cross-cutting through the coating (Figure 6), indicating that the coatings developed in this study strongly stuck on the CRS surface (good adhesion).

\subsection{Electroactivity of EPI and EPGN coatings}

Cyclic voltammetry (CV) has been widely used to characterize the electrochemical properties of electroactive polymers. In this study, the polymers were

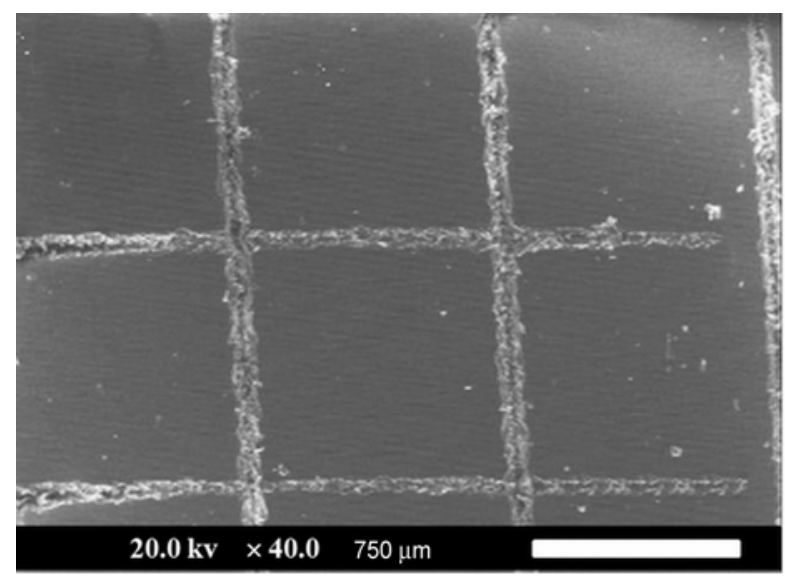

a)

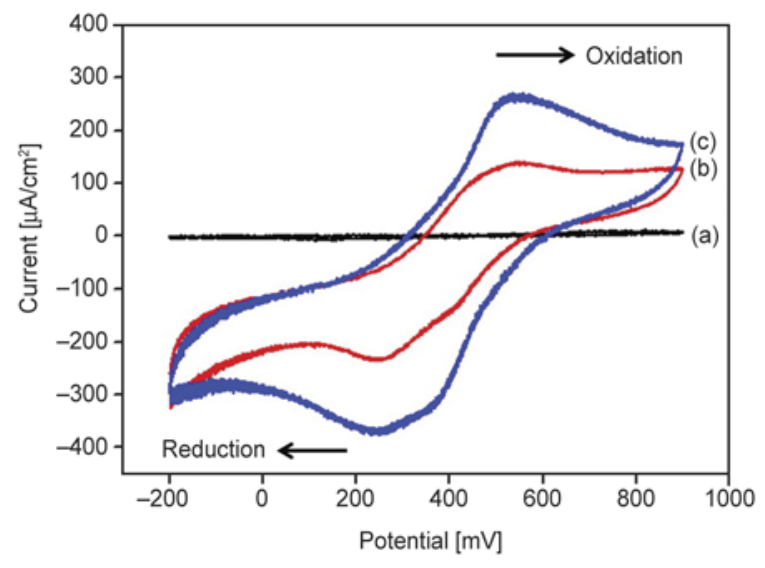

Figure 7. Redox behavior of (a) NEPI-coated, (b) EPIcoated, and (c) EPGN1-coated electrode measured in $1.0 \mathrm{M} \mathrm{H}_{2} \mathrm{SO}_{4}$ aqueous solution

characterized by $\mathrm{CV}$ using a three-electrode electrochemical cell. As shown in Figure 7, the electrochemical CV results indicate that the EPGN materials (e.g., EPGN1) in the form of a coating showed a single oxidation peak, which was similar to the case of the EPI [17]. EPGN1 showed an oxidation current $\left(I_{\mathrm{ox}}\right)$ of $271.9 \mu \mathrm{A} / \mathrm{cm}^{2}$ and a reduction current $\left(I_{\text {red }}\right)$ of $376.6 \mu \mathrm{A} / \mathrm{cm}^{2}$; the latter was smaller than that of the EPI $\left(I_{\text {ox }}=141.3 \mu \mathrm{A} / \mathrm{cm}^{2}, I_{\text {red }}=236.8 \mu \mathrm{A} / \mathrm{cm}^{2}\right)$. However, NEPI showed null zero redox current. This implies that the incorporation of the ACAT into the polyimide introduces electroactivity in the as-prepared polyimide. The introduction of graphene into the EPI matrix results in EPGN materials with higher electroactivity than that of the EPI.

We therefore infer that coatings produced from EPGN materials may provide enhanced corrosion protection as a result of synergistic effects of creating a passive metal oxide layer and the barrier properties that the graphene nanosheets provide to hinder oxygen migration. A series of electrochemical

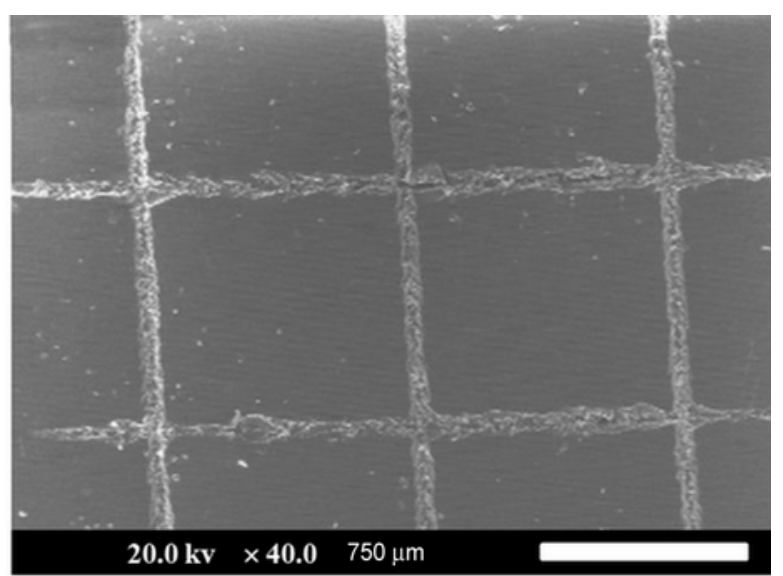

b)

Figure 6. SEM images of (a) EPI-coated on CRS and (b) EPGN1-coated on CRS after testing for adhesion 
standard corrosion measurements (e.g., potentiodynamic and electrochemical impedance measurements) and gas barrier measurements are discussed in the following sections as evidence.

\subsection{Potentiodynamic measurements}

The polarization curves for EPI and a series of EPGN coatings on CRS coupons recorded after $30 \mathrm{~min}$ of immersion in a $3.5 \mathrm{wt} \%$ aqueous $\mathrm{NaCl}$ electrolyte are illustrated. Figure 8 shows the Tafel lines (a), (b), (c), and (d) for the uncoated, EPIcoated, EPGN0.5-coated, and EPGN1-coated CRS electrode, respectively, at $500 \mathrm{mV} / \mathrm{min}$. The corrosion parameters calculated from the Tafel plots for several composite materials are summarized in Table 1; generally, a higher $E_{\text {corr }}$ and $R_{\mathrm{p}}$, and a lower $I_{\text {corr }}$ and $R_{\text {corr }}$ indicate better corrosion protection.

The values of polarization resistance, $R_{\mathrm{p}}$, were evaluated from the Tafel plots, according to the SternGeary equation (Equation (3)) [41]:

$$
R_{\mathrm{p}}=\frac{b_{\mathrm{a}} b_{\mathrm{c}}}{2.303\left(b_{\mathrm{a}}+b_{\mathrm{c}}\right)} \cdot I_{\mathrm{corr}}
$$

where $I_{\text {corr }}$ is the corrosion current determined from the intersection of the linear portions of the anodic and cathodic curves, and $b_{\mathrm{a}}$ and $b_{\mathrm{c}}$ are anodic and

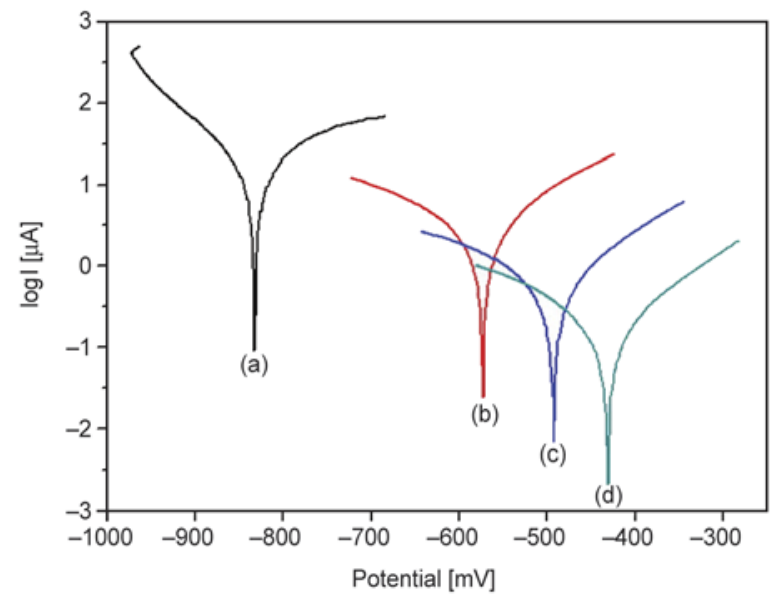

Figure 8. Tafel plots for (a) bare, (b) EPI-coated, (c) EPGN0.5-coated, and (d) EPGN1-coated CRS electrodes at $25 \pm 0.5^{\circ} \mathrm{C}$ cathodic Tafel slopes $(\Delta E / \Delta \log I)$, respectively. The protection efficiency $\left(P_{\mathrm{EF}}[\%]\right)$ values were estimated using the Equation (4) [42]:

$$
P_{\text {EF }}[\%]=100 \frac{R_{\mathrm{p}}^{-1}(\text { uncoated })-R_{\mathrm{p}}^{-1}(\text { coated })}{R_{\mathrm{p}}^{-1}(\text { coated })}
$$

The results in Figure 8 and Table 1 indicate that the EPI-coated CRS coupon shows a higher $E_{\text {corr }}$ value than does the uncoated CRS, which is consistent with the results of earlier studies [15-18]. Moreover, the EPGN materials showed a higher $E_{\text {corr }}, R_{\mathrm{p}}$, and $P_{\mathrm{EF}}$ and lower $I_{\text {corr }}$ values than does the EPI. For example, the EPGN1-coated CRS has an $E_{\text {corr }}$ of $-432 \mathrm{mV}$, Icorr of $0.15 \mu \mathrm{A} / \mathrm{cm}^{2}, R_{\mathrm{p}}$ of $165.29 \mathrm{k} \Omega \cdot \mathrm{cm}^{2}, R_{\text {corr }}$ of $0.14 \mathrm{MPY}$, and $P_{\mathrm{EF}}$ of $98.79 \%$, which are over twice those of the EPIcoated electrode. On the other hand, corrosion current values of the EPGN coatings on CRS were found to decrease gradually with a further increase in graphene loading.

\subsection{Electrochemical impedance measurements}

Electrochemical impedance spectroscopy (EIS) is used to examine the activity difference between the CRS surface upon EPI and EPGN coating treatment. Impedance is a complex resistance when alternating current flows through a circuit made of capacitors, resistors, or insulators, or any of their combination [43]. EIS measurement results in currents over a wide range of frequencies. To obtain the Randles circuit parameters, fitting of the model to the experimental data should be performed using complex nonlinear least-squares procedures available in numerous EIS data fitting computer programs. For the simulation studies, corrosion of metals is modeled with an equivalent circuit (called a Randles circuit), as illustrated in Figure 9, which is made of a double-layer capacitor in parallel with a charge transfer resistor and connected in series with an electrolyte solution resistor. The impedance $(Z)$ depends

\begin{tabular}{|c|c|c|c|c|c|c|}
\hline \multirow[b]{2}{*}{ Sample code } & \multicolumn{4}{|c|}{ Electrochemical corrosion measurements ${ }^{\mathrm{a}}$} & \multirow{2}{*}{$\begin{array}{l}\mathbf{P}_{\mathbf{E F}} \\
{[\%]}\end{array}$} & \multirow{2}{*}{$\begin{array}{c}\text { Thickness } \\
{[\mu \mathrm{m}]}\end{array}$} \\
\hline & $\begin{array}{c}E_{\text {corr }} \\
{[m V \text { vs } S C E]}\end{array}$ & $\begin{array}{c}R_{p} \\
{\left[\mathrm{k} \Omega \cdot \mathrm{cm}^{2}\right]}\end{array}$ & $\begin{array}{c}\mathbf{I}_{\text {corr }} \\
{\left[\mu \mathrm{A} / \mathbf{c m}^{2}\right]}\end{array}$ & $\begin{array}{c}\mathbf{R}_{\text {corr }} \\
{[\text { MPY] }}\end{array}$ & & \\
\hline CRS & -832 & 2.00 & 14.50 & 13.50 & - & - \\
\hline EPI & -573 & 11.10 & 2.75 & 2.56 & 81.98 & $32 \pm 2$ \\
\hline EPGN0.5 & -493 & 52.17 & 0.55 & 0.51 & 96.17 & $31 \pm 2$ \\
\hline EPGN1 & -432 & 165.29 & 0.15 & 0.14 & 98.79 & $33 \pm 2$ \\
\hline
\end{tabular}

Table 1. Electrochemical corrosion measurements of bare CRS, EPI, EPGN0.5 and EPGN1 coated electrodes

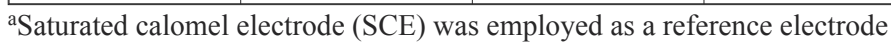




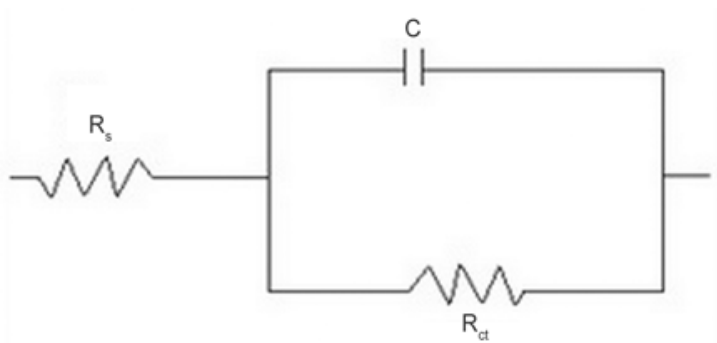

Figure 9. Randles equivalent circuit used for modeling impedance measurements (EIS)

on the charge transfer resistance $\left(R_{\mathrm{ct}}\right)$, solution resistance $\left(R_{\mathrm{S}}\right)$, capacitance of the electrical double layer, and frequency of the AC signal $(\omega)$ (Equation (5):

$Z=Z^{\prime}+j Z^{\prime \prime}=R_{\mathrm{s}} \frac{R_{\mathrm{ct}}}{1+\left(R_{\mathrm{ct}} C_{\mathrm{dl}} \omega\right)^{2}}+\frac{j R_{\mathrm{ct}}^{2} C_{\mathrm{dl}} \omega}{1+\left(R_{\mathrm{ct}} C_{\mathrm{dl}} \omega\right)^{2}}$

The fitting data fitted well to all the experimental electrochemical data. The high-frequency intercept is equal to the solution resistance, and the low-frequency intercept is equal to the sum of the solution and charge transfer resistances [44]. In general, a larger semicircle diameter (charge transfer resistance) represents a smaller corrosion rate.

Figure 10 shows the Nyquist plots of the four measured samples. The first sample (curve a) is uncoated CRS. A series of samples denoted as (curve b), (curve c), and (curve d) represent CRS-coated by EPI, EPGN0.5, and EPGN1, respectively. The corrosion test on these samples immersed in $3.5 \mathrm{wt} \%$ $\mathrm{NaCl}$ aqueous electrolyte for $30 \mathrm{~min}$ is followed by EIS analysis. The charge transfer resistances of all samples, as determined by subtracting the intersection of the high-frequency end from the low-frequency end of the semicircle arc with the real axis,

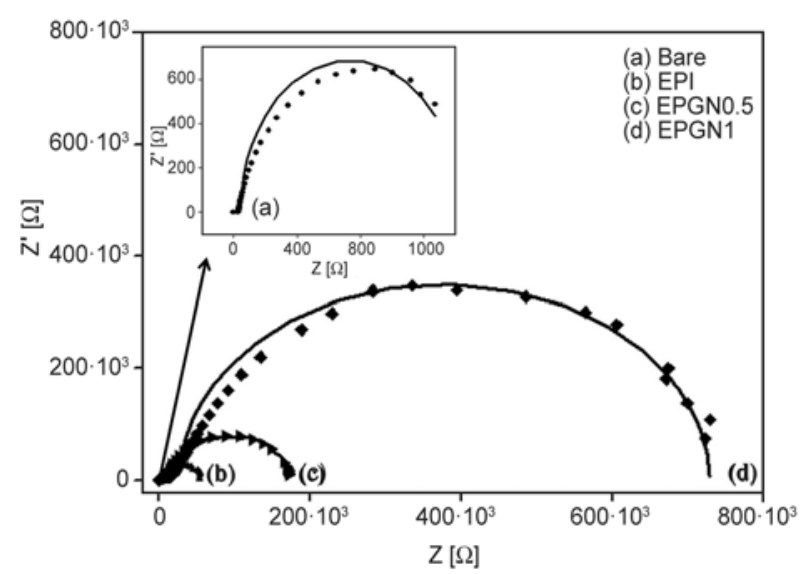

Figure 10. Nyquist plots for (a) bare, (b) EPI-coated, (c) EPGN0.5-coated, and (d) EPGN1-coated CRS electrodes

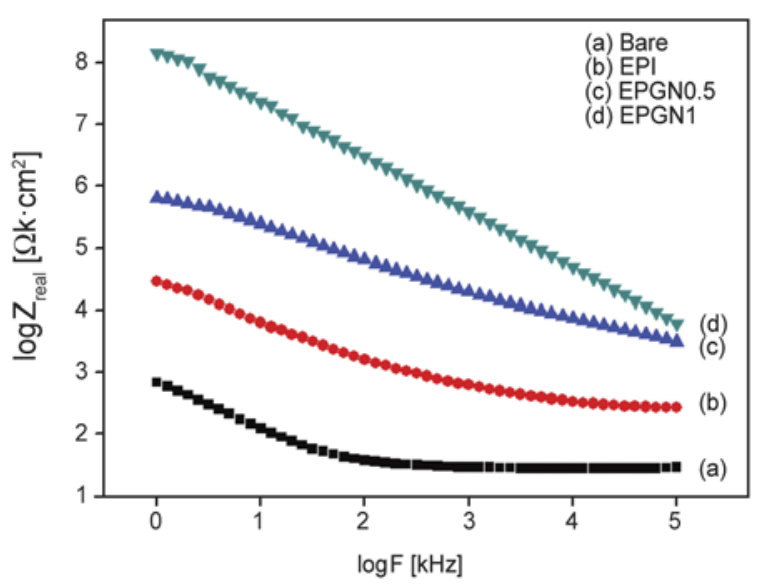

Figure 11. Bode plots for (a) bare, (b) EPI-coated, (c) EPGN0.5-coated, and (d) EPGN1-coated CRS electrodes

are $1.27,54.69,170$, and $728 \mathrm{k} \Omega \cdot \mathrm{cm}^{2}$, respectively. EIS Bode plots (impedance vs. frequency) of all samples are shown in Figure 11. $Z_{\text {real }}$ is a measure of corrosion resistance [45]. Low $Z_{\text {real }}$ value could be brought about by very high capacitance and/or very low resistance of the coating [46]. Large value of the capacitance has been related to the high extent at which water has penetrated the coating [47]. In the case of Bode plots, the value of $Z_{\text {real }}$ at the lowest frequency also represents the corrosion resistance. The Bode magnitude plots for uncoated CRS and CRS-coated by EPI, EPGN0.5, and EPGN1 shows $Z_{\text {real }}$ values of $2.8,4.5,5.8$, and $8.1 \mathrm{k} \Omega \cdot \mathrm{cm}^{2}$, respectively, at low frequency end. These results clearly demonstrate that the EPGN1 coating protects the CRS electrode against corrosion better than the EPI and EPGN0.5 coatings.

The increase in the impedance values at high graphene concentrations in various frequency regions could be interpreted as the barrier effect of the graphene nanosheets dispersed in the composites. Visual observation of the corrosion products clearly reveal that the EPGN samples exhibiting corrosion protection have a grayish oxide layer over the bare exposed CRS surface, similar to what was observed by Wessling [48, 49], in the case of PANI dispersion coatings on steel. The barrier effect of the EPGN materials as compared to that of the EPI may be due to the dispersed graphene in the EPI matrix, which increased the tortuosity of the diffusion pathway of $\mathrm{O}_{2}$ molecules $[39,50]$, as shown in Figure 12. They are further evidenced by the observations on the CRS surface and gas permeability studies of coat- 


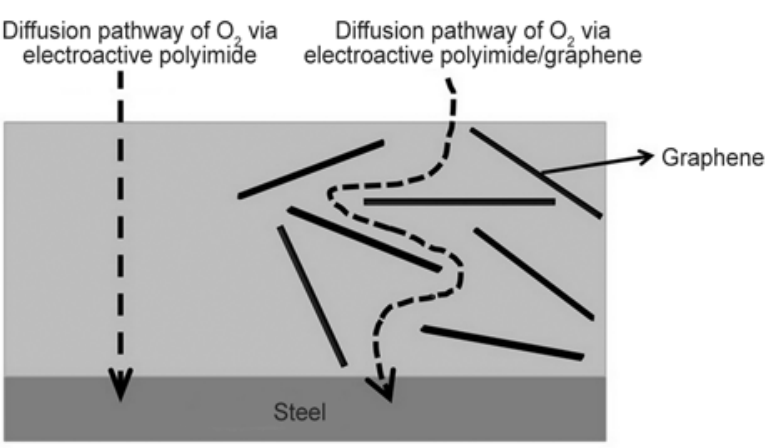

Figure 12. Schematic representation of $\mathrm{O}_{2}$ molecules following a tortuous path through an EPI and EPGN materials

ings and membranes, as discussed in Sections 3.6 and 3.7.

\subsection{Observations of the CRS surface}

The EPI and EPGN coatings might induce the formation of a layer of passivation oxide, $\mathrm{Fe}_{2} \mathrm{O}_{3} / \mathrm{Fe}_{3} \mathrm{O}_{4}$, through the redox reaction between the quinonediimine segment (Figure 6) of EPI/EPGN and the metal surface. It should be emphasized that the advantage of this newly developed EPGN materials is that it not only provides passive protection but also acts as an active functional polymer materials that can induce the formation of another inert protection layer, i.e., $\mathrm{Fe}_{2} \mathrm{O}_{3}$ and $\mathrm{Fe}_{3} \mathrm{O}_{4}$.

Next, the as-prepared sample coatings were stored for $24 \mathrm{~h}$ at room temperature and then removed using a razor knife. Visual observation of the passivation oxide layers revealed a grayish oxide layer over the CRS surface under the EPGN1 coating on CRS. It is similar to what was observed by Wessling $[48,51]$. The SEM images revealed that the oxide layers were formed between the EPGN1 coating and

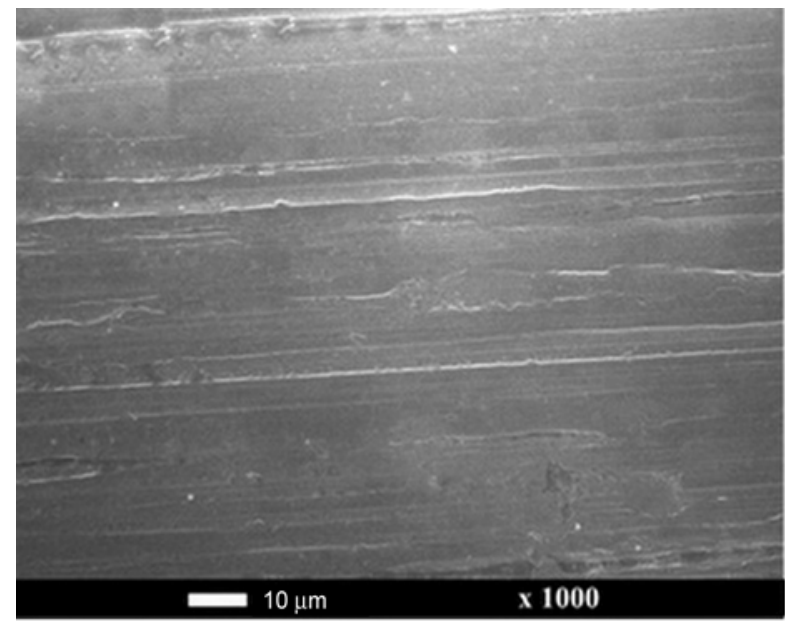

a)

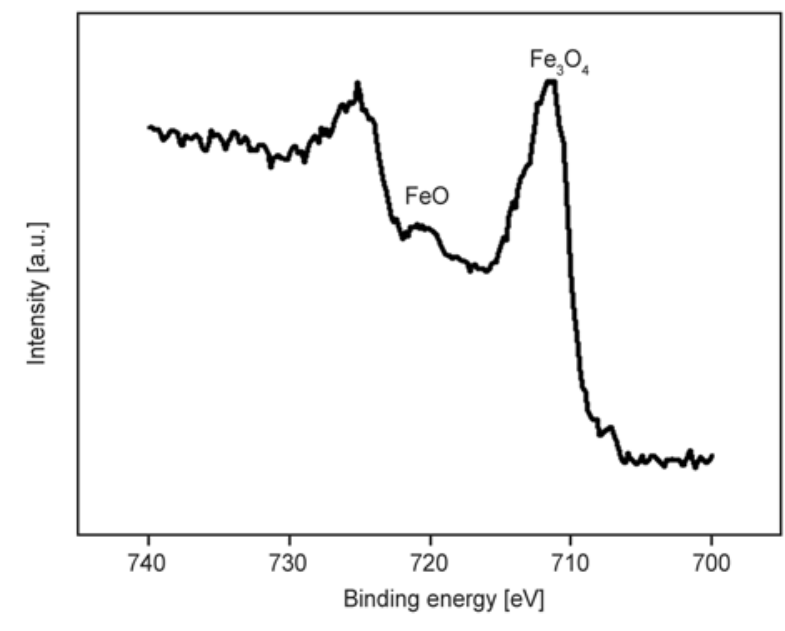

Figure 14. ESCA Fe 2p core-level spectra of EPI

the CRS surface (Figure 13b), but we could not observe the same image from the pure CRS surface (Figure 13a).

In addition to the SEM observations, the chemical nature of the passivation oxide layers was determined by ESCA. The plots of binding energy vs. intensity for the iron oxide layers are shown in Figure 14. The passivation oxide layers exhibited the $\mathrm{Fe} 2 \mathrm{p}^{3 / 2}$ peak binding energy of $\mathrm{Fe}_{2} \mathrm{O}_{3}$ at $710.9 \mathrm{eV}$; $\mathrm{FeO}$ at $709.6 \mathrm{eV}$; and $\mathrm{Fe}_{3} \mathrm{O}_{4}$ at $710.3 \mathrm{eV}$. The $\mathrm{Fe} 2 \mathrm{p}$ spectra of $\mathrm{FeO}$ and $\mathrm{Fe}_{3} \mathrm{O}_{4}$ were, and hence, it was difficult to distinguish between the two oxides. The $2 \mathrm{p}^{3 / 2}$ binding energy was about 725.2 and $711.6 \mathrm{eV}$. These findings indicated that the passive oxide layer is predominately composed by $\mathrm{Fe}_{2} \mathrm{O}_{3}$ above a very thin $\mathrm{Fe}_{3} \mathrm{O}_{4}$ layer, which was consistent with the results of previous studies [48, 51-53].

The enhanced corrosion protection of EPI and EPGN coatings was found to be associated with the formation of passivation protective metal oxide lay-

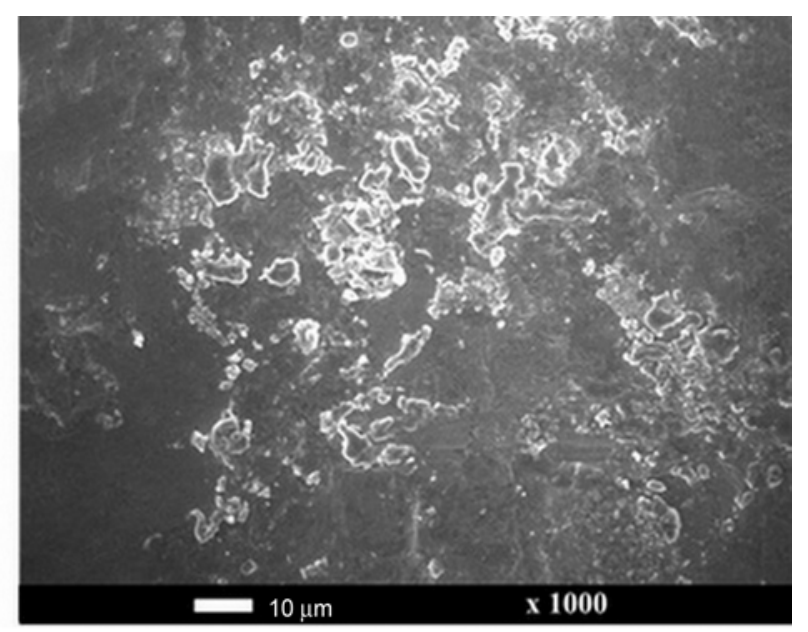

b)

Figure 13. SEM images for (a) polished CRS metal and the surface of the (b) EPGN1 coating on the CRS metal 


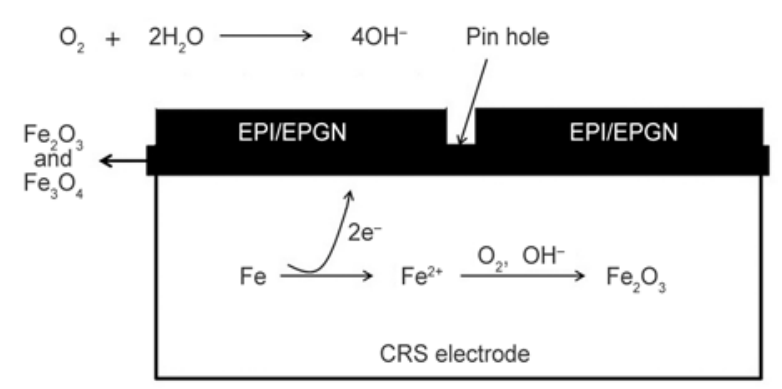

Figure 15. Schematic diagram of mechanism of CRS passivation by EPI/EPGN coatings

ers, induced by the redox catalytic properties of asprepared EPI and EPGN coatings, as shown in Figure 15.

\subsection{Gas barrier of EPI and EPGN membranes}

The presence of filler, inorganic or organic, in the polymer matrix usually constitutes a solid barrier in the path of the gas molecules passing through the polymer. A more tortuous path is thus forced upon the gas molecules passing through the polymeric matrix, retarding the progress of the phenomenon. The more tortuous the path the longer it takes for the gas molecules to pass through the material, resulting in a macroscopically observed reduced permeability. The higher the filler-matrix interfacial area and aspect ratio of the filler, the more tortuous the path, hence the greater the decrease in permeability. Graphene-based polymer nanocomposites had been examined intensively for their gas barrier rate's enhancements, due to the high aspect ratio of welldispersed graphene nanosheets [54]. In this study, molecular barrier measurements were performed on membranes of EPI and EPGN materials prepared to

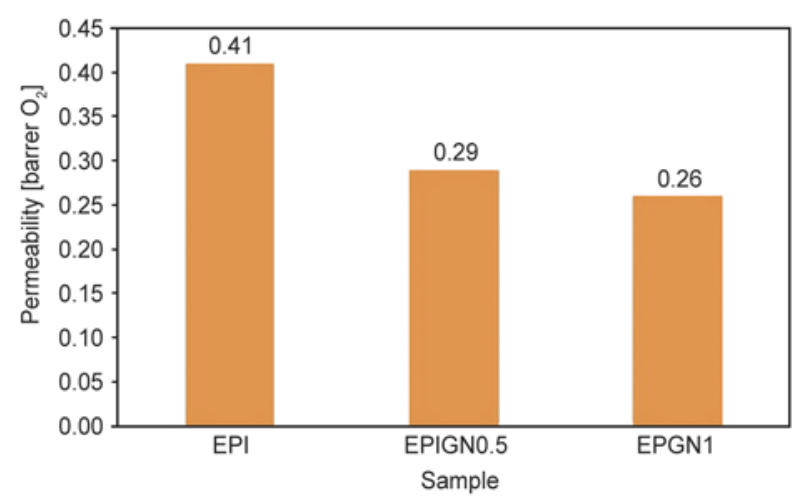

Figure 16. Permeability of oxygen as a function of graphene content in the EPGN materials a film thickness of $\sim 50 \mu \mathrm{m}$. Compared to EPI, EPGN membranes at low graphene loading (e.g., $0.5 \mathrm{wt} \%$ ) shows about $29 \%$ reduction in $\mathrm{O}_{2}$ permeability, as shown in Figure 16. The decrease in gas permeability is attributed to the barrier properties of the layers of graphene nanosheets dispersed in the composites. It should be noted that a further increase in graphene loading in the EPGN materials up to $1 \mathrm{wt} \%$ results in a further decrease in gas permeability.

\section{Conclusions}

Electroactive polyimide/graphene nanocomposite (EPGN) materials were successfully prepared by thermal imidization. The structure and electroactivity of the EPGN materials were investigated by FTIR and CV. The dispersion capability of the carboxyl-graphene nanosheets in the EPI matrix was observed by TEM studies. The nanocomposites consisting of the EPI matrix and well-dispersed graphene nanosheets were found to exhibit excellent anticorrosive properties resulted from enhanced gas barrier properties.

\section{Acknowledgements}

The authors acknowledge the financial support from the Ministry of Education, Taiwan, R.O.C. (NSC 101-2113-M033-005-MY1, 101-3113-P-002-026 and 102-2622-E-007016-CC1); The Center-of-Excellence (COE) Program on Membrane Technology from the Ministry of Education (MOE), R.O.C.; The Department of Chemistry at CYCU (CYCU-01RD-RA002-11235); and The Center for Nanotechnology and Biomedical Technology at CYCU.

\section{References}

[1] Lee C-H., Kato M., Usuki A.: Preparation and properties of bio-based polycarbonate/clay nanocomposites. Journal of Materials Chemistry, 21, 6844-6847 (2011). DOI: $10.1039 / \mathrm{C} 1 \mathrm{JM} 10087 \mathrm{D}$

[2] Usuki A., Hasegawa N., Kato M., Kobayashi S.: Polymer-clay nanocomposites. Advances in Polymer Science, 179, 135-195 (2005).

DOI: $10.1007 / \mathrm{b} 104481$

[3] Pötschke P., Krause B., Buschhorn S. T., Köpke U., Müller M. T., Villmow T., Schulte K.: Improvement of carbon nanotube dispersion in thermoplastic composites using a three roll mill at elevated temperatures. Composites Science and Technology, 74, 78-84 (2013). DOI: 10.1016/j.compscitech.2012.10.010

[4] Minus M. L., Chae H. G., Kumar S.: Polyethylene crystallization nucleated by carbon nanotubes under shear. ACS Applied Materials Interfaces, 4, 326-330 (2012). DOI: 10.1021/am2013757 
[5] Hu X-L., Hou G-M., Zhang M-Q., Rong M-Z., Ruan W-H., Giannelis E-P.: A new nanocomposite polymer electrolyte based on poly(vinyl alcohol) incorporating hypergrafted nano-silica. Journal of Materials Chemistry, 22, 18961-18967 (2012).

DOI: $10.1039 / \mathrm{C} 2 \mathrm{JM} 33156 \mathrm{~J}$

[6] Chen J. H., Rong M. Z., Ruan W. H., Zhang M. Q.: Interfacial enhancement of nano- $\mathrm{SiO}_{2} /$ polypropylene composites. Composites Science and Technology, 69, 252-259 (2009).

DOI: $10.1016 /$ j.compscitech.2008.10.013

[7] Hojjati B., Charpentier P. A.: Synthesis of $\mathrm{TiO}_{2}$-polymer nanocomposite in supercritical $\mathrm{CO}_{2}$ via RAFT polymerization. Polymer, 51, 5345-5351 (2010).

DOI: $10.1016 /$ j.polymer.2010.09.050

[8] Tang C-W., Li B., Sun L., Lively B., Zhong W-H.: The effects of nanofillers, stretching and recrystallization on microstructure, phase transformation and dielectric properties in PVDF nanocomposites. European Polymer Journal, 48, 1062-1072 (2012).

DOI: $10.1016 /$ j.eurpolymj.2012.04.002

[9] Yang C-P., Su Y-Y., Guo W., Hsiao S-H.: Synthesis and properties of novel fluorinated polynaphthalimides derived from 1,4,5,8-naphthalenetetracarboxylic dianhydride and trifluoromethyl-substituted aromatic bis(ether amine)s. European Polymer Journal, 45, 721729 (2009).

DOI: $10.1016 /$ j.eurpolymj.2008.12.013

[10] Lin S., Guo R., Lan J., Chen S., Shang J.: Synthesis and properties of novel thermoplastic poly(ester-etherimide) elastomers derived from 4,4'-bis(N-trimellitimide)-diphenylether unit with excellent thermal stability. Journal of Macromolecular Science Part A: Pure and Applied Chemistry, 49, 1052-1060 (2012). DOI: 10.1080/10601325.2012.728473

[11] Tsuchiya T., Maeda S., Tsukada Y.: Packaging substrate applications of ultra low CTE polyimide. Journal of Photopolymer Science and Technology, 25, 359364 (2012).

DOI: 10.2494/photopolymer.25.359

[12] Popovici D., Hulubei C., Cozan V., Lisa G., Bruma M.: Polyimides containing cycloaliphatic segments for low dielectric material. High Performance Polymers, 24, 194-199 (2012). DOI: $10.1177 / 0954008311435798$

[13] Wang Z. Y., Yang C., Gao J. P., Lin J., Meng X. S., Wei Y., Li S.: Electroactive polyimides derived from aminoterminated aniline trimer. Macromolecules, 31, 27022704 (1998).

DOI: $10.1021 / \mathrm{ma} 971782 \mathrm{~s}$

[14] Chao D., Cui L., Lu X., Mao H., Zhang W., Wei Y.: Electroactive polyimide with oligoaniline in the main chain via oxidative coupling polymerization. European Polymer Journal, 43, 2641-2647 (2007).

DOI: $10.1016 /$ j.eurpolymj.2007.03.048
[15] Huang H-Y., Huang T-C., Yeh T-C., Tsai C-Y., Lai CL., Tsai M-H., Yeh J-M., Chou Y-C.: Advanced anticorrosive materials prepared from amine-capped aniline trimer-based electroactive polyimide-clay nanocomposite materials with synergistic effects of redox catalytic capability and gas barrier properties. Polymer, 52, 2391-2400 (2011).

DOI: 10.1016/j.polymer.2011.03.030

[16] Weng C-J., Huang J-Y., Huang K-Y., Jhuo Y-S., Tsai M-H., Yeh J-M.: Advanced anticorrosive coatings prepared from electroactive polyimide- $\mathrm{TiO}_{2}$ hybrid nanocomposite materials. Electrochimica Acta, 55, 84308438 (2010).

DOI: $10.1016 /$ j.electacta.2010.07.063

[17] Huang K-Y., Jhuo Y-S., Wu P-S., Lin C-H., Yu Y-H., Yeh J-M.: Electrochemical studies for the electroactivity of amine-capped aniline trimer on the anticorrosion effect of as-prepared polyimide coatings. European Polymer Journal, 45, 485-493 (2009).

DOI: $10.1016 /$ j.eurpolymj.2008.10.033

[18] Huang T-C., Yeh T-C., Huang H-Y., Ji W-F., Chou YC., Hung W-I., Yeh J-M., Tsai M-H.: Electrochemical studies on aniline-pentamer-based electroactive polyimide coating: Corrosion protection and electrochromic properties. Electrochimica Acta, 56, 10151-10158 (2011).

DOI: $10.1016 /$ j.electacta.2011.08.114

[19] Bao C., Song L., Wilkie C. A., Yuan B., Guo Y., Hu Y., Gong X.: Graphite oxide, graphene, and metal-loaded graphene for fire safety applications of polystyrene. Journal of Materials Chemistry, 22, 16399-16406 (2012). DOI: $10.1039 / \mathrm{C} 2 \mathrm{JM} 32500 \mathrm{D}$

[20] Potts J. R., Shankar O., Du L., Ruoff R. S.: Processing-morphology-property relationships and composite theory analysis of reduced graphene oxide/natural rubber nanocomposites. Macromolecules, 45, 60456055 (2012). DOI: $10.1021 / \mathrm{ma300706k}$

[21] Jiang X., Drzal L. T.: Exploring the potential of exfoliated graphene nanoplatelets as the conductive filler in polymeric nanocomposites for bipolar plates. Journal of Power Sources, 218, 297-306 (2012). DOI: 10.1016/j.jpowsour.2012.07.001

[22] Li M., Huang X., Wu C., Xu H., Jiang P., Tanaka T.: Fabrication of two-dimensional hybrid sheets by decorating insulating PANI on reduced graphene oxide for polymer nanocomposites with low dielectric loss and high dielectric constant. Journal of Materials Chemistry, 22, 23477-23484 (2012).

DOI: $10.1039 / \mathrm{C} 2 \mathrm{JM} 34683 \mathrm{D}$

[23] Kim B. K., Jang M. W., Park H. C., Jeong H. M., Kim E. Y.: Effect of graphene doping of holographic polymer-dispersed liquid crystals. Journal of Polymer Science Part A: Polymer Chemistry, 50, 1418-1423 (2012). DOI: $10.1002 /$ pola.25909 
[24] Longun J., Iroh J. O.: Nano-graphene/polyimide composites with extremely high rubbery plateau modulus. Carbon, 50, 1823-1832 (2012).

DOI: $10.1016 /$ j.carbon.2011.12.032

[25] Yoonessi M., Shi Y., Scheiman D. A., Lebron-Colon M., Tigelaar D. M., Weiss R. A., Meador M. A.: Graphene polyimide nanocomposites; Thermal, mechanical, and high-temperature shape memory effects. ACS Nano, 6, 7644-7655 (2012).

DOI: $10.1021 / \mathrm{nn} 302871 \mathrm{y}$

[26] Chen D., Zhu H., Liu T.: In situ thermal preparation of polyimide nanocomposite films containing functionalized graphene sheets. ACS Applied Materials and Interfaces, 2, 3702-3708 (2010).

DOI: $10.1021 / \mathrm{am} 1008437$

[27] Xu Z., Buehler M. J.: Geometry controls conformation of graphene sheets: Membranes, ribbons, and scrolls. ACS Nano, 4, 3869-3876 (2010).

DOI: $10.1021 / \mathrm{nn} 100575 \mathrm{k}$

[28] Wei Y., Yang C., Ding T.: A one-step method to synthesize N,N'-bis(4'-aminophenyl)-1,4-quinonenediimine and its derivatives. Tetrahedron Letters, 37, 731-734 (1996).

DOI: 10.1016/0040-4039(95)02300-3

[29] Huang K-Y., Shiu C-L., Wu P-S., Wei Y., Yeh J-M., Li W-T.: Effect of amino-capped aniline trimer on corrosion protection and physical properties for electroactive epoxy thermosets. Electrochimica Acta, 54, 54005407 (2009).

DOI: 10.1016/j.electacta.2009.04.030

[30] Hummer W., Offerman R.: Preparation of graphitic oxide. Journal of the American Chemical Society, 80, 1339 (1958). DOI: $10.1021 / \mathrm{ja} 01539 \mathrm{a} 017$

[31] Yang D., Velamakanni A., Bozoklu G., Park S., Stoller M., Piner R. D., Stankovich S., Jung I., Field D. A., Ventrice Jr C. A., Ruoff R. S.: Chemical analysis of graphene oxide films after heat and chemical treatments by X-ray photoelectron and micro-Raman spectroscopy. Carbon, 47, 145-152 (2009).

DOI: $10.1016 /$ j.carbon.2008.09.045

[32] Liu W-R., Kuo S-L., Lin C-Y., Chiu Y-C., Su C-Y., Wu H-C., Hsieh C-T.: Characterization and electrochemical behavior of graphene-based anode for li-ion batteries. The Open Materials Science Journal, 5, 236-241 (2011). DOI: $10.2174 / 1874088 X 01105010236$

[33] Kuo S-L., Liu W-R., Kuo C-P., Wu N-L., Wu H-C.: Lithium storage in reduced graphene oxides. Journal of Power Sources, 244, 552-556 (2013). DOI: $10.1016 /$ j.jpowsour.2013.01.186

[34] Chang K-C., Lai M-C., Peng C-W., Chen Y-T., Yeh JM., Lin C-L., Yang J-C.: Comparative studies on the corrosion protection effect of DBSA-doped polyaniline prepared from in situ emulsion polymerization in the presence of hydrophilic $\mathrm{Na}^{+}-\mathrm{MMT}$ and organophilic organo-MMT clay platelets. Electrochimica Acta, 51, 5645-5653 (2006).

DOI: $10.1016 /$ j.electacta.2006.02.039
[35] Huang K-Y., Shiu C-L., Su Y-A., Yang C-C., Yeh J-M., Wei Y., Lee K-R.: Preparation and gas transport properties of dense fluoroaniline copolymer membranes. Journal of Membrane Science, 339, 171-176 (2009). DOI: $10.1016 /$ j.memsci.2009.04.046

[36] Tseng I-H., Chang J-C., Huang S-L., Tsai M-H.: Enhanced thermal conductivity and dimensional stability of flexible polyimide nanocomposite film by addition of functionalized graphene oxide. Polymer International, 62, 827-835 (2013).

DOI: $10.1002 /$ pi.4375

[37] Luong N. D., Hippi U., Korhonen J. T., Soininen A. J., Ruokolainen J., Johansson L-S., Nam J. D., Sinh L. H., Seppälä J.: Enhanced mechanical and electrical properties of polyimide film by graphene sheets via in situ polymerization. Polymer, 52, 5237-5242 (2011). DOI: 10.1016/j.polymer.2011.09.033

[38] Shi H., Li Y., Guo T.: In situ preparation of transparent polyimide nanocomposite with a small load of graphene oxide. Journal of Applied Polymer Science, 128, 31633169 (2013). DOI: 10.1002/app.38519

[39] Tsai M-H., Tseng I-H., Liao Y-F., Chiang J-C.: Transparent polyimide nanocomposites with improved moisture barrier using graphene. Polymer International, 62, 1302-1309 (2013).

DOI: $10.1002 /$ pi.4421

[40] Beving D. E., McDonnell A. M. P., Yang W. S., Yan Y. S.: One general solution formulation for aluminum alloy AA-2024-T3, AA-5052-H32, AA-6061-T4, and AA7075-T6. Journal of the Electrochemical Society, 153, B325-B329 (2006). DOI: $10.1149 / 1.2207845$

[41] Stern M., Geary A. L.: Electrochemical polarization I. A theoretical analysis of the shape of polarization curves. Journal of the Electrochemical Society, 104, 56-63 (1957).

DOI: $10.1149 / 1.2428496$

[42] Bockris J., Reddy K. N.: Modern electrochemistry. Plenum Press, New York (1976).

[43] Park S-M., Yoo J-S.: Electrochemical impedance spectroscopy for better electrochemical measurements. Analytical Chemistry, 75, 455A-461A (2003). DOI: $10.1021 / \mathrm{ac} 0313973$

[44] Amirudin A., Thierry D.: Application of electrochemical impedance spectroscopy to study the degradation of polymer-coated metals. Progress in Organic Coatings, 26, 1-28 (1995).

DOI: $10.1016 / 0300-9440(95) 00581-1$

[45] Zucchi F., Grassi V., Frignani A., Monticelli C., Trabanelli G.: Electrochemical behaviour of a magnesium alloy containing rare earth elements. Journal of Applied Electrochemistry, 36, 195-204 (2006). DOI: $10.1007 / \mathrm{s} 10800-005-9053-3$ 
[46] Kannan M. B., Gomes D., Dietzel W., Abetz V.: Polyoxadiazole-based coating for corrosion protection of magnesium alloy. Surface and Coatings Technology, 202, 4598-4601 (2008).

DOI: $10.1016 /$ j.surfcoat.2008.03.027

[47] Rammelt U., Reinhard G.: Application of electrochemical impedance spectroscopy (EIS) for characterizing the corrosion-protective performance of organic coatings on metals. Progress in Organic Coatings, 21, 205 226 (1992).

DOI: 10.1016/0033-0655(92)87005-U

[48] Wessling B.: Passivation of metals by coating with polyaniline: Corrosion potential shift and morphological changes. Advanced Materials, 6, 226-228 (1994). DOI: 10.1002/adma.19940060309

[49] Wessling B.: Scientific and commercial breakthrough for organic metals. Synthetic Metals, 85, 1313-1318 (1991).

DOI: $10.1016 / \mathrm{S} 0379-6779(97) 80254-8$

[50] Tseng I-H., Liao Y-F., Chiang J-C., Tsai M-H.: Transparent polyimide/graphene oxide nanocomposite with improved moisture barrier property. Materials Chemistry and Physics, 136, 247-253 (2012).

DOI: $10.1016 /$ j.matchemphys.2012.06.061
[51] Wessling B.: Corrosion prevention with an organic metal (polyaniline): Surface ennobling, passivation, corrosion test results. Materials and Corrosion, 47, 439445 (1996). DOI: $10.1002 /$ maco.19960470804

[52] Lu W-K., Elsenbaumer R. L., Wessling B.: Corrosion protection of mild steel by coatings containing polyaniline. Synthetic Metals, 71, 2163-2166 (1995). DOI: 10.1016/0379-6779(94)03204-J

[53] Fahlman M., Jasty S., Epstein A. J.: Corrosion protection of iron/steel by emeraldine base polyaniline: An $\mathrm{X}$-ray photoelectron spectroscopy study. Synthetic Metals, 85, 1323-1326 (1997). DOI: $10.1016 / \mathrm{S} 0379-6779(97) 80256-1$

[54] Potts J. R., Dreyer D. R., Bielawski C. W., Ruoff R. S.: Graphene-based polymer nanocomposites. Polymer, 52, 5-25 (2011). DOI: $10.1016 /$ j.polymer.2010.11.042 